\title{
Can a temporal processing deficit account for dyslexia?
}

\author{
KEITH RAYNER, ALEXANDER POLLATSEK, and ALEXANDER B. BILSKY \\ University of Massachusetts, Amherst, Massachusetts
}

\begin{abstract}
In this comment, we argue that although Farmer and Klein (1995) have provided a valuable review relating deficits in nonreading tasks and dyslexia, their basic claim that a "temporal processing deficit" is one possible cause of dyslexia is somewhat vague. We argue that "temporal processing deficit" is never clearly defined. Furthermore, we question some of their assumptions concerning an auditory temporal processing deficit related to dyslexia, and we present arguments and data that seem inconsistent with their claims regarding how a visual temporal processing deficit would manifest itself in dyslexic readers. While we agree that some dyslexics have visual problems, we conclude that problems with reading caused by the visual mechanisms that Farmer and Klein postulate are quite rare.
\end{abstract}

Farmer and Klein (1995) have provided an interesting and informative review of the evidence consistent with the association of a temporal processing deficit with developmental dyslexia. As with research in many areas of psychological inquiry, prevailing views on the underlying problem for developmental dyslexia have followed the swing of the pendulum. Twenty-five years ago, the prevailing view was that some type of deficit in visual perception was responsible for the inability of certain children to learn to read well. Following extensive tests of the perceptual deficit view, the conventional wisdom became that the dyslexics' problem was not in the realm of visual perception and was not due to a general cognitive deficit, but rather to some type of linguistic deficit (for summaries, see Liberman \& Shankweiler, 1985; Shankweiler \& Crain, 1986; Vellutino, 1979). The view that developmental dyslexia primarily represents some type of language-specific problem has been accepted by many researchers in the field (see Shankweiler \& Crain, 1986), but more recently challenges to this view have come from a number of sources. In their review article, Farmer and Klein have presented an overview of studies purporting to demonstrate either a perceptual or a temporal processing deficit associated with developmental dyslexia.

Our view, which Farmer and Klein appear to share, is that there are many causes of dyslexia (see also Martin, 1995) and that it is futile to search for the underlying cause of developmental dyslexia. However, they appear to be-

Preparation of this article was supported by a National Institute of Mental Health Research Scientist Award (MH01255) to the first author, by Grant HD 26765 from the National Institutes of Health to the first and second authors, and by a National Science Foundation fellowship to the third author. We thank Mary Farmer, Ray Klein, Jim Neely, and an anonymous reviewer for their helpful comments on an earlier version of the article. Requests for reprints should be addressed to K. Rayner, Department of Psychology, University of Massachusetts, Amherst, MA 01003 (e-mail: rayner@psych.umass.edu). lieve that a "temporal processing deficit," while not ubiquitous, may be a major reason for dyslexia. Their review discusses two primary mechanisms by which temporal processing deficits could cause reading problems. First, they argue that dyslexics exhibit temporal processing deficits in the auditory domain and attempt to promote these temporal deficits as at least an underlying cause of the language deficits indicated above and thus as a root cause of dyslexia. Second, they argue that dyslexics exhibit visual temporal processing deficits, and they attempt to use these deficits as causal factors to explain some reading problems, independent of the influences of the auditory temporal processing deficits.

One point that is not particularly clear from Farmer and Klein's article concerns the proportion of dyslexic readers who may have each of these temporal processing deficits at the heart of their reading problem. With respect to this point, Farmer and Klein suggest that "a temporal processing deficit might manifest itself in the various modalities and affect reading ability to different degrees and in different ways" (p. 479). As indicated above, they suggest ways in which (1) an auditory temporal deficit may result in a phonemic deficit, which is characteristic of many developmental dyslexics, and (2) developmental dyslexia might arise from a visual temporal processing deficit. We suspect that they believe (like most researchers) that (1), above, is the primary cause for dyslexia, and thus that the auditory temporal deficit is a reinterpretation of the languagedeficit hypothesis. While some researchers (e.g., Lovegrove, Martin, \& Slaghuis, 1986) have reported that as many as $75 \%$ of the subjects they tested had a visual processing deficit, most attempts to categorize developmental dyslexia into different subtypes have generally indicated that the proportion of dyslexics with some type of visual, perceptual, or spatial deficit is quite low (ranging from $4 \%$ to $16 \%$; see Thomson, 1984). Thus, it would appear that visual processing deficits would account for only a relatively small percentage of the dyslexic population. 


\section{General Comments}

Farmer and Klein's article is an ambitious undertaking, and the attempt to deal with so much literature is praiseworthy. However, we feel that there are several basic problems that make Farmer and Klein's account not totally satisfying. Most stem from the fact that "temporal processing deficit" is never clearly defined. While it clearly applies operationally to tasks generally involving simple stimuli that are brief and presented in close temporal proximity, it is often unclear whether the putative problem involves processing a brief and/or complex stimulus, processing order relations among stimuli, or some combination or conjunction of the two. For example, if order-judgment deficits occur for only certain types of stimuli (e.g., consonants), then what exactly is the deficit? Thus, even if Farmer and Klein were correct in proposing that the fundamental problem with a subset of dyslexics is an underlying temporal processing deficit rather than a language deficit, it is not clear that this diagnosis is helpful at the present level at which this hypothesis is being advocated.

A symptom of this lack of clarity relates to not knowing how to understand Farmer and Klein's claims about the relationship between auditory and visual temporal processing deficits. Are they claiming that visual and auditory deficits stem from the same source, different sources, or both? At times in the article, it appears that these deficits are thought of as stemming from a common problem in an underlying "timing mechanism"; at other times they appear to have different sources. We would guess that the authors' position is that both problems could exist - a modality-independent temporal deficit and modality-specific deficits.

As more of our research has dealt with the visual aspects of reading, we will focus our argument on the claims that visual temporal processing deficits are an important problem in dyslexia. However, we first wish to make a few comments about the claims of auditory temporal processing deficits.

\section{Dyslexia and an Auditory Temporal Processing Deficit}

We take the central part of Farmer and Klein's argument about audition to be that the problems that appear to be merely language problems may stem from a more fundamental temporal processing deficit. This claim can be broken down into two components. The first is that the difficulties that these subjects experience in language-related tasks will appear in other tasks not related to language, and hence it is unparsimonious to postulate that the deficits are confined to a completely encapsulated "language module." This seems quite reasonable to us, and the arguments are quite cogent for why the language module (1) would not be fully encapsulated but instead would use "chips" that other tasks use as well, and (2) may have been designed by evolution prior to the evolution of language. It is also true that there is quite a bit of imprecision in current language-deficit hypotheses about exactly what a "language deficit" is (or what language deficits are). Thus, attempting to tease apart language deficits into more basic components seems like a step in the right direction.

The problem with Farmer and Klein's proposal, however, is that their alternative hypothesis of a "temporal processing deficit" does not seem to be much better defined than the language-deficit hypotheses. Essentially, Farmer and Klein posit that a temporal processing deficit will produce a problem in understanding phonemes (since speech is a signal that occurs in time). While the hypothesis predicts that symptoms outside the language domain will be observable, it does not really help much toward understanding why this produces a deficit in reading. In addition, the temporal processing deficit does not really relate in any serious way to subtypes of language deficits. In several studies (e.g., Manis, Seidenberg, Doi, McBrideChang, \& Peterson, in press; Murphy \& Pollatsek, 1994), there appear to be two clusters of language-related problems. One is related to vocal production and is typically indexed by the rapid automatic naming task. The other relates to phonemic awareness (and presumably perceptual problems) and is typically indexed by such tasks as phoneme deletion. Both problems could somehow be plausibly related to temporal or timing problems, but, as they appear to be at least somewhat independent, they presumably would be related to two types of temporal processing problems. Farmer and Klein's lack of precision makes it hard to think about how to extend their arguments to apply to questions such as these. More generally, there are already many studies in which reading problems are correlated with a battery of oral language-production, oral languagereception, and word-identification measures. It is not at all clear how the auditory temporal processing deficit is going to elucidate the complex pattern of results that is usually obtained (and is reasonably consistent across studies - see Manis et al., in press, and Murphy \& Pollatsek, 1994).

\section{Dyslexia and a Visual Temporal Processing Deficit}

Farmer and Klein argue that deficits in the visual system that sends information to the brain may lead to poor reading performance. The specific hypothesis that they discuss (Breitmeyer, 1980, 1989; Breitmeyer \& Ganz, 1976) is based on the distinction between transient and sustained channels of the visual information-processing system. Here again, Farmer and Klein are not really very clear as to what they mean by a temporal processing deficit, nor do they distinguish it from a sequential processing deficit. However, they suggest two specific ways in which a visual temporal processing deficit might manifest itself in dyslexic readers. First, they posit that a deficit in the transient system will release the sustained system from inhibition and lead to increased persistence from the preceding eye fixation, resulting in interference with the information processed on the current eye fixation. Second, they posit that decreased transient activity will reduce the amount of parafoveal information available during reading. We will discuss each of these suggestions. 
Eye-movement problems. It is a well-known fact that developmental dyslexics' eye movements while reading text are quantitatively different from those of normal readers (Elterman, Abel, Daroff, Dell'Osso, \& Bornstein, 1980; Rayner, 1978, 1985; Rubino \& Minden, 1973): in comparison with normal readers, dyslexic readers' average fixation durations are longer, their average saccade length is shorter, and the average number of regressions is much larger. But such differences could be attributed to a number of different causal factors, including persistence from preceding fixations (as per Farmer and Klein's suggestion), difficulty in processing words in text, and faulty control of the saccadic eye-movement system. The point is that we cannot tell merely by examining the eye movements of dyslexic readers while they read.

Although Farmer and Klein are not very specific about exactly how a visual temporal processing deficit would affect eye-movement behavior during reading, their suggestion is reminiscent of a suggestion made previously by Pavlidis $(1981,1985)$ that some type of central sequencing deficit may manifest itself in the eye-movement behavior of dyslexic readers. Although Farmer and Klein's proposal (i.e., that a visual temporal processing deficit will result in persistence from the preceding fixation, thus interfering with the processing of the current fixation) may differ somewhat from Pavlidis's (i.e., that a sequential processing deficit will manifest itself in erratic eye movements), on the surface it seems that they have similarities. We suspect that it is instructive to review Pavlidis's findings in light of the issue that we raised earlier concerning the proportion of dyslexic readers who manifest certain characteristics.

Pavlidis (1981, 1985) examined the eye movements of dyslexic readers when they were engaged in a nonreading sequential processing task. He appropriately noted that any study based on reading experiments alone would be open to a number of interpretations. However, he reasoned that if the cause of dyslexia was due to a sequential disability, one would expect that such a disability would manifest itself not only in reading, but in other tasks in which sequencing and eye movements were important as well. Therefore, he asked normal and dyslexic readers to move their eyes to fixate continuously on a fixation target that jumped from left to right or from right to left across a screen. Pavlidis's primary finding was that when the target moved from left to right, dyslexic readers made significantly more right-to-left saccades than did normal readers. He concluded that erratic eye movements (moving from right to left when the task called for movements from left to right) were characteristic of dyslexic readers.

Pavlidis's results are consistent with some case studies (Ciuffreda, Bahill, Kenyon, \& Stark, 1976; Pirozzolo \& Rayner, 1978; Zangwill \& Blakemore, 1972) in which dyslexic readers have been described as having a tendency to move their eyes from right to left during reading. However, on the basis of Pavlidis's (1981) original report, a number of attempts were undertaken to confirm his findings. None of these studies (Black, Collins, De Roach, \& Zubrick, 1984; Brown et al., 1983; Olson, Kliegl, \& Davidson, 1983; Stanley, Smith, \& Howell, 1983) were able to replicate
Pavlidis's findings: there was no indication in any of these studies that dyslexic readers differed from normals in terms of the frequency of regressions when moving their eyes from left to right in Pavlidis's task. Other studies (Adler-Grinberg \& Stark, 1978; Eskenazi \& Diamond, 1981; Stanley et al., 1983) have also failed to find differences between normal and dyslexic readers' eye-movement patterns in a visual search task.

Perhaps the easiest way to account for the discrepant findings between Pavlidis's research and the failures to replicate his work is that Pavlidis's subject-selection process somehow resulted in a larger number of dyslexic readers with visual deficits than is typical of the general population of dyslexics (Pollatsek, 1983; Rayner, 1985). It is mentioned in some of the studies that generally failed to replicate Pavlidis's findings that a few of their subjects did yield results like those reported by Pavlidis.

We return now to the specific suggestion that Farmer and Klein have made regarding the eye fixations of dyslexic readers. Specifically, their point is that there may be persistence from a preceding fixation that interferes with the processing of a current fixation. This implies that (1) dyslexics' eye fixations during reading may be longer than those for normal readers, or (2) dyslexics make more eye fixations than do normal readers. As we have noted, both are indeed true, but the reason is not at all clear and could be due to a number of factors. It has been demonstrated, however, that when dyslexic readers are given age-appropriate reading material their eye-movement characteristics do not differ from those of normal readers of that age (Pirozzolo, 1979), and that when normal readers are given text that is too difficult their eye-movement characteristics look very much like those of dyslexic readers (Rayner, 1986). Furthermore, when dyslexic readers' eye movements are compared with those of control subjects of similar reading age, their average fixation durations and eye-movement characteristics do not differ (Hyönä \& Olson, 1994, in press). Finally, Hyönä and Olson found that fixation durations in visual search do not differ between dyslexics and normal readers. Thus, given the above data, the most likely explanation for most dyslexic readers' longer fixation durations when reading is that they are having difficulty processing individual words and not that persistence from the preceding fixation is interfering with the processing being attempted in the current fixation.

Parafoveal information during reading. Although Farmer and Klein are a bit unclear about how a visual temporal deficit would affect eye fixations during reading, they are quite clear with respect to the issue of processing parafoveal information: they specifically suggest that dyslexic readers process less parafoveal information on each eye fixation than do normal readers. On this issue, there are some relevant data obtained by using the eye-contingent moving-window paradigm (McConkie \& Rayner, 1975; Rayner \& Bertera, 1979) which estimates the size of the effective visual field during reading. In the moving-window paradigm, readers' eye movements are monitored. On each fixation, text is exposed within a window region around the fixation point; wherever the reader fixates, the text is 
available; outside the window, the text is replaced by letters or Xs. The size of the window can be determined either by letter spaces (a 17-character window would mean that 8 letters to the left and 8 letters to the right of fixation were within the window) or by words (in a one-word window, only the fixated word is available, while in a twoword window, the fixated word and the word to the right of fixation are available). As one would expect, reading speed increases as the size of the window increases. This increase is the result of both shorter fixations and fewer fixations. These changes occur because the preview of words in the parafovea allows for faster processing of the words when they are fixated later and because parafoveal extraction of information allows for some words to be skipped (Blanchard, Pollatsek, \& Rayner, 1989). For normal skilled readers, the window extends about 15 character spaces to the right of fixation (or about two words to the right of the fixated word) and 4 character spaces to the left (see Rayner \& Pollatsek, 1989, for a more complete description).

Using the moving-window paradigm, Rayner, Murphy, Henderson, and Pollatsek (1989) compared the performance of 3 dyslexic readers ${ }^{1}$ with that of some normal readers. Figure 1 shows the reading rate as a function of window size for 2 of the dyslexic readers and the controls (the third dyslexic reader will be discussed below). Although the dyslexic readers reached asymptote in reading rate with a two-word window and the normal readers did not reach asymptote until the window had three words, the general patterns were quite similar. These data thus indicate that the effective visual field for the dyslexic readers might be a bit smaller than that of normal readers, but they do not necessarily mean that the dyslexic readers are processing parafoveal information less effectively. In partic-

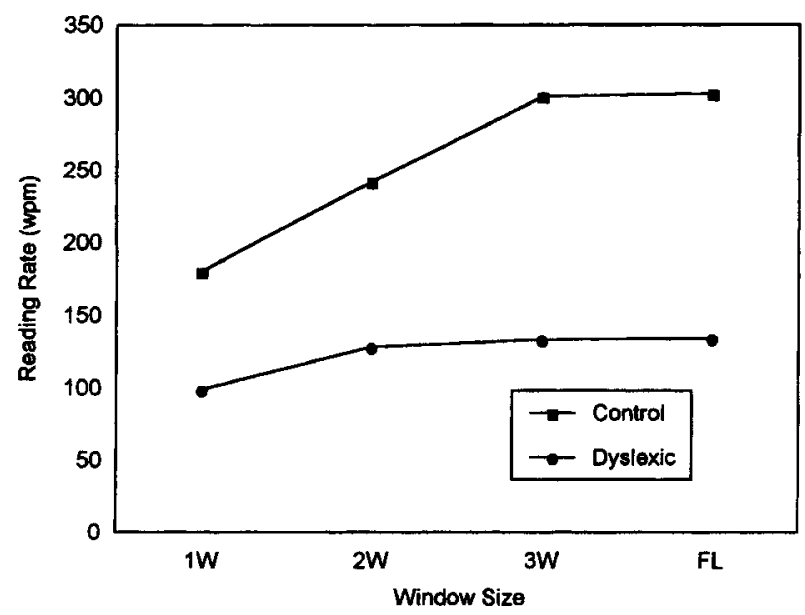

Figure 1. Reading rate (in words per minute) as a function of window size for normal control subjects and dyslexic readers. $A$ window size of $1 \mathrm{~W}$ means that only the fixated word was available within the window, $2 \mathrm{~W}$ means that the fixated word and one word to the right of fixation were available, and $3 \mathrm{~W}$ means that the fixated word plus two words to the right of fixation were available. $F L=$ full-line condition, in which the entire line of text was available. Letters outside the window were replaced with Xs. ular, in experiments using the eye-contingent display change paradigm, Rayner (1986), Inhoff, Pollatsek, Posner, and Rayner (1989), and Henderson and Ferreira (1990) all demonstrated that readers obtain less parafoveal information when the fixated word is difficult to process than when the fixated word is easy to process. In other words, processing difficulty associated with the fixated word shrinks the size of the effective visual field.

Figure 2 shows average fixation durations as a function of window size for Rayner et al.'s dyslexic and normal readers. Figure 3 shows data for 8 disabled readers 2 in a study reported by Underwood and Zola (1986). In their study, all letters beyond 3,5 , or 7 letters to the right of fixation were replaced by random letters. The typical finding in movingwindow studies like these is that as the window size increases, fixation duration decreases until asymptote is reached (or the point at which readers can typically obtain all of the information that they would normally obtain on a fixation). In both figures, the normal, control subjects (or good readers) show the typical pattern of data. But, note that in both Figure 2 and Figure 3 the disabled readers' pattern is like that of the normal readers and that fixation durations are markedly longer when information beyond the window is removed. ${ }^{3}$ If dyslexic readers do not get good parafoveal information during a fixation, they should not show the better reading with increased window size that they do.

These data lead us to believe that while the effective visual field may be somewhat smaller for dyslexic readers than for skilled readers, it is not because they process parafoveal information less effectively than normal readers, but rather that they have difficulty in processing the fixated word. With respect to this point, there is some irony in the fact that Geiger and Lettvin (1987) proposed that the cause of dyslexia was that dyslexic readers processed parafoveal information more effectively than did normal readers; they suggested that dyslexics' efficient parafoveal processing interfered with foveal processing, and that this is what caused their reading problem. Indeed, Geiger, Lettvin, and Fahle (1994) argued that dyslexic readers could markedly increase their reading ability by cutting a small window in an index card and reading the material inside the window as it was moved across text. However, among the researchers who have made claims about the underlying cause of dyslexia, there remains considerable controversy with regard to the basic result that dyslexic readers process parafoveal information more effectively than do normal readers. While Perry, Dember, Warm, and Sacks (1989) reported results that were consistent with Geiger and Lettvin's (1987), others (Goolkasian \& King, 1990; Klein, Berry, Briand, D’Entremont, \& Farmer, 1990; Slaghuis, Lovegrove, \& Freestun, 1992) were unable to replicate their main finding. Finally, the third dyslexic subject, the focus of Rayner et al.'s (1989) article, showed characteristics that were somewhat like those of Geiger and Lettvin's subjects: he could identify parafoveal words and letters better than normal readers and, when reading with a moving window, he read better with a small window than with a large one. ${ }^{4}$ However, we would argue that he was atypical of dyslexic 
readers. Rayner et al. argued that he had a selective attention deficit which made it difficult for him to focus attention on the fixated word.

Paradigms and percentages. Researchers who specialize in using one particular type of paradigm, or who are well known for research on a certain topic, typically find a high percentage of dyslexic readers who have difficulty in their paradigm (i.e., they do much more poorly than normal readers). We have mentioned two examples where this is the case: (1) Pavlidis's finding that dyslexic readers have erratic eye movements due to an underlying sequential processing deficit, and (2) Geiger and Lettvin's finding that dyslexic readers process parafoveal information better than do normal readers (which leads to interference in the processing of foveal information). In each case, we have seen that there has been considerable difficulty in replicating the results; while there may be some evidence that is consistent with the specific claim, for the most part the overall data have not been consistent. Let us just mention three other findings, each of which has not yet been reported by more than one research group. First, in Fischer's lab (see Biscaldi, Fischer, \& Aiple, 1994; Fischer, Biscaldi, \& Otto, 1993; Fischer \& Weber, 1990), which specializes in the study of "express saccades" (short-latency eye movements), it has been found that a high percentage of dyslexics make more express saccades than do normal readers. This finding has been attributed to a deficit in the attention system which makes it difficult to disengage foveal attention. ${ }^{5}$ Second, in Stein's lab (see Eden, Stein, Wood, \& Wood, 1994; Stein, 1994), which specializes in binocular control, a high percentage of dyslexics have been found to have difficulty in holding their eyes steady (as is necessary in reading). And, third, in Lovegrove's lab (see Lovegrove et al., 1986), which specializes in contrast sensitivity, a high percentage of dyslexics have been found to have

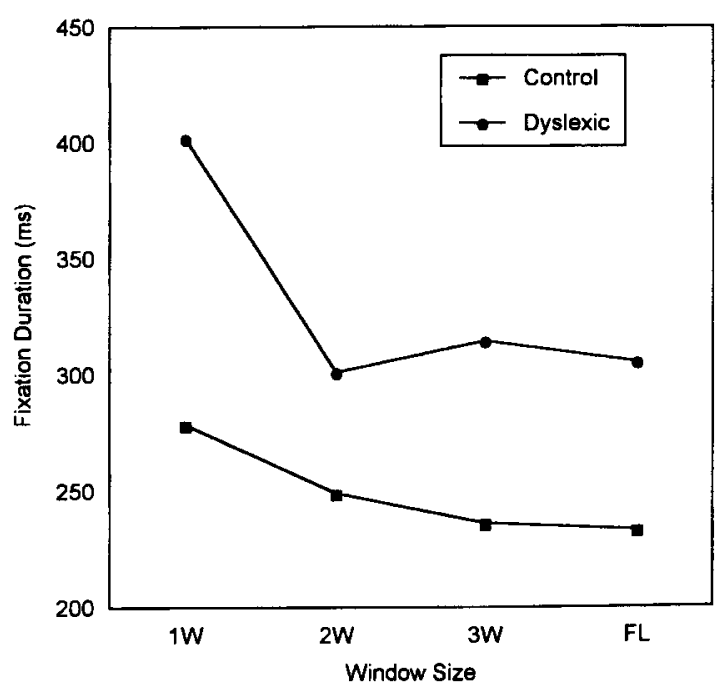

Figure 2. Fixation duration (in milliseconds) as a function of window size for control and dyslexic readers in the Rayner et al. (1989) study. Letters outside of the window were replaced with Xs.

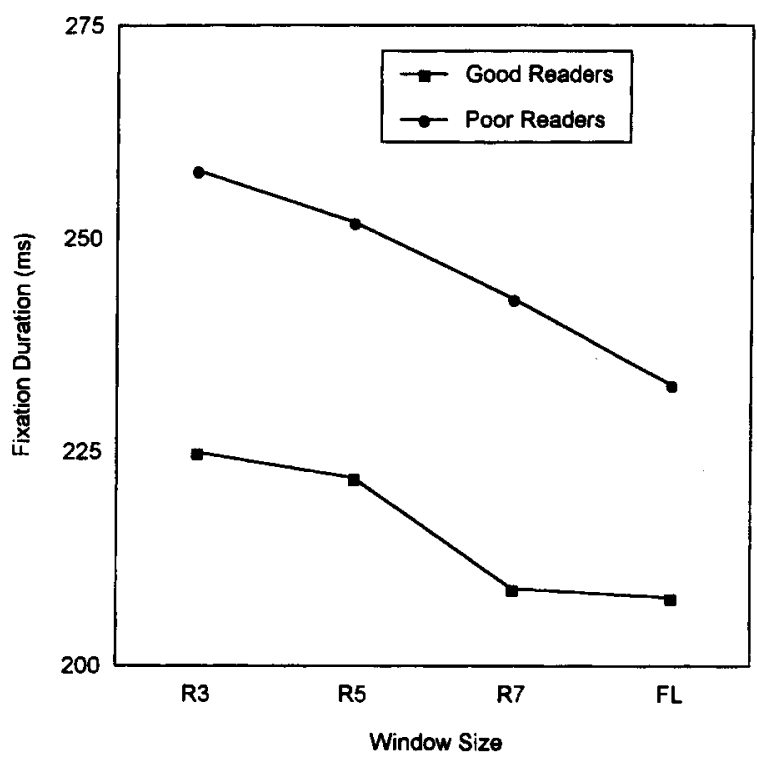

Figure 3. Fixation duration (in milliseconds) as a function of window size for good and poor readers in the Underwood and Zola (1986) study. In the $\mathbf{R 3}$ condition, three letters to the right of fixation were available, with all other letters to the right replaced with random letters. In the $R 5$ and $R 7$ conditions, five or seven letters, respectively, to the right of fixation were available and all other letters were replaced with random letters. FL = full-line condition.

lower visual contrast sensitivity for low spatial and temporal frequencies.

At this point, it is too early to really evaluate the reliability of the three findings above; systematic attempts to replicate the findings in other labs are not widespread or have not yet been undertaken. However, given the controversy concerning the findings of Pavlidis (1981) and Geiger and Lettvin (1987), we think it is fair to ask the following question. Why are certain results obtained primarily in the labs of specialists on specific topics but not always in other labs? We think this is one of the great mysteries of research on dyslexia. The rule almost seems to be that if you expect to find a deficit in your paradigm, you will find it. On the other hand, researchers who are experts with a given paradigm may be able to uncover subtle effects. Another great mystery is why there are so many contradictory findings is the field of dyslexia research (see Rayner $\&$ Pollatsek, 1989). In this regard, as we noted earlier, we think that Farmer and Klein (1995) are quite reasonable in that they acknowledge that there may be many underlying factors contributing to dyslexia.

\section{Summary}

Farmer and Klein have done a great service in putting together a large literature relating deficits in nonreading tasks and dyslexia. They argue convincingly that dyslexia can have causes that are more general than the processing of language. In particular, they argue convincingly that examining deficits in nonlanguage auditory tasks could help to elucidate the nature of language problems in dyslexia. 
However, at present, the "temporal processing deficit" hypothesis is too vague to be of much help in understanding these language problems and how they causally relate to reading problems. They also argue that visual temporal problems underlie dyslexia to some extent. We feel, in this case, that the argument is on less solid ground. While there are undoubtedly some dyslexics who have visual problems, most of the research on dyslexia suggests that problems with reading caused by the visual mechanisms that Farmer and Klein postulate are quite rare.

\section{REFERENCES}

AdLER-GrindBerg, D., \& Stark, L. (1978). Eye movements, scanpaths, and dyslexia. American Journal of Optometry \& Physiological Optics, 55, 557-570.

BISCALDI, M., Fischer, B., \& AIPLE, F. (1994). Saccadic eye movements of dyslexic and normal reading children. Perception, 23, 45-64.

Black, J. L., Collins, D. W. K., De Roach, J. N., \& Zubrick, S. (1984) A detailed study of sequential saccadic eye movements for normal and poor reading children. Perceptual \& Motor Skills, 59, 423-434.

Blanchard, H. E., Pollatsek, A., \& Rayner, K. (1989). Parafoveal processing during eye fixations in reading. Perception \& Psychophysics, 46, 85-94.

BREITMEYER, B. G. (1980). Unmasking visual masking: A look at the "why" behind the veil of "how." Psychological Review, 87, 52-69.

BREITMEYER, B. G. (1989). A visually based deficit in specific reading disability. Irish Journal of Psychology, 10, 534-541.

BREITMEYER, B. G., \& GANZ, L. (1976). Implications of sustained and transient channels for theories of visual pattern masking, saccadic suppression, and information processing. Psychological Review, 83, 1-36.

Brown, B., Haegerstrom-Portnoy, G., Yinglin, C. D., Herron, J., Galin, D., \& Marcus, M. (1983). Predictive eye movements do not discriminate between dyslexic and control children. Neuropsychologia, 21, 121-128.

Ciuffreda, K. J., Bahill, A. T., Kenyon, R. V., \& Stark, L. (1976). Eye movements during reading: Case studies. American Journal of $O p$ tometry \& Physiological Optics, 53, 389-395.

EDEN, G. F., SteIN, J. F., WoOd, H. M., \& Wood, F. B. (1994). Differences in eye movements and reading problems in dyslexic and normal children. Vision Research, 34, 1345-1358.

Elterman, R. D., Abel, L. A., Daroff, R. B., Dell'Osso, L. F., \& BORNSTEIN, J. L. (1980). Eye movement patterns in dyslexic children. Journal of Learning Disabilities, 13, 16-21.

EskenaZI, D., \& Diamond, S. P. (1983). Visual exploration of nonverbal material by dyslexic children. Cortex, 19, 353-370.

FARMER, M. E., \& KLEIN, R. M. (1995). The evidence for a temporal processing deficit linked to dyslexia: A review. Psychonomic Bulletin \& Review, 2, 460-493.

Findlay, J. M. (1992). Programming of stimulus-elicited saccadic eye movements. In K. Rayner (Ed.), Eye movements and visual cognition: Scene perception and reading (pp. 8-30). New York: Springer-Verlag.

Fischer, B., BasCaldi, M., \& OtTo, P. (1993). Saccadic eye movements of dyslexic adult subjects. Neuropsychologia, 31, 887-906.

Fischer, B., \& WEBER, H. (1990). Saccadic reaction times of dyslexic and age-matched normal subjects. Perception, 19, 805-818.

Geiger, G., \& LetT VIN, J. Y. (1987). Peripheral vision in persons with dyslexia. New England Journal of Medicine, 316, 1238-1243.

Geiger, G., LetTVin, J. Y., \& FAHLE, M. (1994). Dyslexic children learn a new visual strategy for reading: A controlled experiment. Vision Research, 34, 1223-1233.

GOOLKASIAN, P., \& KING, J. (1990). Letter identification and lateral masking in dyslexic and average readers. American Journal of Psychology, $103,519-538$

Henderson, J. M., \& Ferreira, F. (1990). Effects of foveal processing difficulty on the perceptual span in reading: Implications for attention and eye movement control. Journal of Experimental Psychology: Learn ing, Memory, \& Cognition, 16, 417-429.
HyöNä, J., \& OLson, R. K. (1994). Dyslexic and normal readers' eye movement patterns in reading, visual search, and tracking. In J. Ygge \& G. Lennerstrand (Eds.), Eye movements in reading (pp. 233-242). Oxford: Pergamon

HYöNÄ, J., \& OLSON, R. K. (in press). Eye fixation patterns among dyslexic and normal readers: Effects of word length and word frequency. Journal of Experimental Psychology: Learning, Memory, \& Cognition.

Inhoff, A. W., Pollatsek, A., Posner, M. I., \& Rayner, K. (1989). Covert attention and eye movements during reading. Quarterly Journal of Experimental Psychology, 41A, 63-89.

KinGstone, A., \& KLEIN, R. M. (1993). What are human express saccades? Perception \& Psychophysics, 54, 260-273.

Klein, R. [M.], Berry, G., Briand, K., D'Entremont, B., \& Farmer, M. [E.] (1990). Letter identification declines with increasing retinal eccentricity at the same rate for normal and dyslexic readers. Perception \& Psychophysics, 47, $601-606$.

Liberman, I. Y., \& Shankweiler, D. (1985). Phonology and the problems of learning to read and write. Remedial \& Special Education, 6, 8-17.

Lovegrove, W. J., Martin, F., \& Slaghuis, W. (1986). A theoretical and experimental case for a visual deficit in specific reading disability. Cognitive Neuropsychology, 3, 225-267.

Manis, F. R., Seidenberg, M. S., Doi, L. M., McBride-Chang, C., \& Petersen, A. (in press). On the basis of two subtypes of developmental dyslexia. Cognition.

Martin, R. C. (1995). Heterogeneity of deficits in developmental dyslexia and implications for methodology. Psychonomic Bulletin \& Review, 2, 494-500.

MCCONKIE, G. W., \& RAYNER, K. (1975). The span of the effective stimulus during a fixation in reading. Perception \& Psychophysics, 17, 578-586.

MurPhy, L., \& Pollatsek, A. (1994). Developmental dyslexia: Heterogeneity without discrete subgroups. Annals of Dyslexia, 44, 120-146.

Olson, R. K., KLIEGL, R., \& DAVIDSON, B. J. (1983). Dyslexic and normal readers' eye movements. Journal of Experimental Psychology: Human Perception \& Performance, 9, 81 6-825.

Pavlidis, G. T. (1981). Do eye movements hold the key to dyslexia? Neuropsychologia, 19, 57-64.

Pavlidis, G. T. (1985). Eye movement differences between dyslexic, normal, and retarded readers while sequentially fixating digits. American Journal of Optometry \& Physiological Optics, 62, 820-832.

Perry, A. R., Dember, W. N., Warm, J. S., \& Sacks, J. G. (1989). Letter identification in normal and dyslexic readers: A verification. $B u l$ letin of the Psychonomic Society, 27, 445-448.

Pirozzolo, F. J. (1979). The neuropsychology of developmental reading disorders. New York: Praeger.

Pirozzolo, F. J., \& RaYNer, K. (1978). Disorders of oculomotor scanning and graphic orientation in developmental Gerstmann syndrome. Brain \& Language, 5, 119-126.

Pollatsek, A. (1983). What can eye movements tell us about dyslexia? In K. Rayner (Ed.), Eye movements in reading: Perceptual and language processes (pp. 511-521). New York: Academic Press.

RAYNER, K. (1978). Eye movements in reading and information processing. Psychological Bulletin, 85, 618-660.

RAYNER, K. (1985). Do faulty eye movements cause dyslexia? Developmental Neuropsychology, 1, 3-15.

RAYNER, K. (1986). Eye movements and the perceptual span in beginning and skilled readers. Journal of Experimental Child Psychology, 41,211-236.

RAYNER, K., \& BERTERA, J. H. (1979, October 26). Reading without a fovea. Science, 206, 468-469.

Rayner, K., Murphy, L. A., Henderson, J. M., \& Pollatsek, A. (1989). Selective attentional dyslexia. Cognitive Neuropsychology, 6, 357-378.

RaYNer, K., \& POlLATSEK, A. (1989). The psychology of reading. Englewood Cliffs, NJ: Prentice-Hall.

Rubino, C. A., \& Minden, H. A. (1973). Analysis of eye-movements in children with a reading disability. Cortex, 9, 217-220.

Shankweiler, D., \& CRAIN, S. (1986). Language mechanisms and reading disorder: A modular approach. Cognition, 24, 139-168. 
Slaghuis, W. L., Lovegrove, W. J., \& Freestun, J. (1992). Letter recognition in peripheral vision and metacontrast masking in dyslexic and normal readers. Clinical Vision Sciences, 7, 53-65.

Stanley, G., Smith, G. A., \& Howell, E. A. (1983). Eye-movements and sequential tracking in dyslexic and control children. British Journal of Psychology, 74, 181-187.

STEIN, J. F. (1994). Binocular control in dyslexics. In J. Ygge \& G. Lennerstand (Eds)., Eye movements in reading (pp. 273-290). Oxford: Pergamon.

Thomson, M. (1984). Developmental dyslexia. London: Arnold.

UNDERWOOD, N. R., \& ZoLA, D. (1986). The span of letter recognition of good and poor readers. Reading Research Quarterly, 21, 6-19.

Vellutino, F. R. (1979). Dyslexia: Theory and research. Cambridge, MA: MIT Press.

Zangwill, O. L., \& BlaKemore, C. (1972). Dyslexia: Reversal of eye movements during reading. Neuropsychologia, 10, 371-373.

\section{NOTES}

1. The dyslexic readers were all adults, who had been diagnosed as dyslexics in their youth and had attended special schools for dyslexics. Their IQ scores were above 100 , but they read at approximately the seventhgrade level. Their listening comprehension scores were markedly higher than their reading scores.
2. The disabled readers in Underwood and Zola's study were fifthgrade children who were reading between 1 and 2.5 years behind their expected reading level.

3. The average fixation durations in the Rayner et al. study are longer than those in the Underwood and Zola study. This is probably due to the fact that, in the Underwood and Zola study, normal text was always available to the left of fixation, which, except for the fixated word, was not the case in the Rayner et al. study.

4. This improved performance with smaller windows occurred only when the letters outside of the window were replaced by Xs. In this condition (unlike the condition in which the letters outside the window are replaced with other letters), the reader is aware of the boundaries of the window of text. Hence, restricting the window apparently helped him only when the restricted region was open to consciousness, apparently by helping him to focus attention to the region around fixation. It should be noted that, in comparison with this dyslexic reader, all normal readers who have been tested over the years in our laboratory read better as the window size is increased (up to about 15 letter spaces to the right of fixation).

5. Actually, there is some controversy over the exact nature of express saccades (see Findlay, 1992; Kingstone \& Klein, 1993).

(Manuscript received April 24, 1995; revision accepted for publication June 22,1995 .) 